\section{FAMILY MEDICINE MUST FIND AND USE ITS POWER TO IMPROVE THE HEALTH OF THE NATION}

Academic health centers (AHCs) are powerful forces in universities, bringing prestige and profitability to higher education. Within this environment, family medicine's vital role in personal and population health can seem secondary or even dismissed as irrelevant with 9 schools still refusing to embrace family medicine. ${ }^{1}$ The reasons for this may be many, with roots deeply embedded in different philosophical, economic, behavioral, or scientific approaches to improving health. However, we in family medicine must own how others view us and become proactive in advocating for our patients. America's health needs the discipline of family medicine to be vibrant, both in communities and in our academic health centers. We thus must embrace change. Finding and leveraging our power is an important first step.

For some, the notion of using power is uncomfortable because of its relationship to the human condition, best summarized by Lord Acton, "Power corrupts and absolute power corrupts absolutely." Yet, those who have risen into the ranks of leadership understand that power is the coin of the realm for achieving results that matter. While Lord Acton's assertion may define the human condition, it is too simplistic to apply to all human actions, especially if the judicious use of power can address injustice and suffering.

We in family medicine must use our power if we hope to improve America's health. At the 2014 ADFM annual meeting, we explored the power of partnerships and how this can be an effective strategy for leveraging power. We learned that as Chairs and Administrators of Departments of Family Medicine (DFMs) our goal should be to organize and use power and partnerships to enhance our departments' ability to produce more and better trained clinicians, teachers, and researchers of family medicine. Our DFMs must create and develop primary care teams who understand the nuance between the personal nature of medicine within a patient-centered medical home and the equally important population and community basis for health.

Where do we find our power? The best examples find it in a life-giving mission that is grounded in the care for others, or notions of justice, love, and respect for others. This type of power is not positional power with the traditional trappings of absolute authority. It is the power wielded in the last century by such luminaries of the human spirit as Martin Luther King and before him, Mahatma (Mohandas) Gandhi. Each of these men started from positions of relative powerlessness. They both lived in societies with power structures that limited their ability to make changes, but they found power in unlikely partners and places.

All of us in family medicine leadership need to cultivate an improved relationship with power.

- Power should be driven by a noble mission that has not drifted to self and/or maintaining the status quo

- Power should build partnerships that ensure fidelity to mission

- Power should be driven by information that increases the pool of meaning within the community rather than serving the needs of special interests

ADFM's members, as leaders in AHCs, have the potential to exert legitimate power within our own environments. Much tension exists today in AHCs attempting to balance the tripartite missions of clinical care, research, and education. ${ }^{2}$ Grumbach and colleagues suggest that $\mathrm{AHC}$ should align these 3 missions into a single mission to improve health and health care for communities through advancing, applying, and disseminating knowledge. ${ }^{3} \mathrm{We}$, as Chairs of DFMs, have power from being part of the AHCs. We must use our voices in a way that can be heard within AHCs, affirming their value but calling them to a higher purpose. This role of "embedded critics" $^{\prime \prime}$ is one we must embrace. ${ }^{4}$

ADFM is committed to partnering with all who share our mission of improving America's health through a health care delivery system that supports accessible, high quality, and affordable health care for all. We will partner with educational and research organizations that support this mission. Most importantly, we hope to partner with patients, community groups, employers, and those who share our concerns about the health of the nation. If we keep patients at the center of our mission, then we will have found our power and begun to use it effectively.

Paul James MD, ADFM President, on bebalf of the ADFM Executive Committee

\section{References}

1. Biggs WS, Bieck AD, Crosley PW, Kozakowski SM. Entry of US medical school graduates into family medicine residencies: 2011-2012. Fam Med. 2012;44(9):620-626.

2. Enders T, Conroy J. Advancing the academic health system for the future: a report for the AAMC AdvisoryPanel on health care. https:// www.aamc.org/initiatives/patientcare/aphc/357864/academichealthsystem.html. 2014. Accessed May 9, 2014. 
3. Grumbach K, Lucey CR, Johnston SC. Transforming from centers of learning to learning health systems: the challenge for academic health centers. JAMA. 2014;311(11):1109-1110.

4. Powers BW, Cassel CK, Jain SH. The power of embedded critics. J Gen Intern Med. 2014.
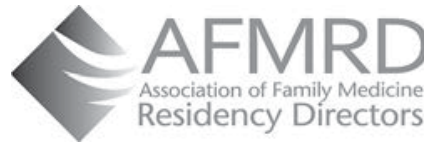
Association of Family Medicine Residency Directors

From the Association of Family Medicine Residency Directors

\section{FROM FAMILY MEDICINE MILESTONES TO ENTRUSTABLE PROFESSIONAL ACTIVITIES (EPAS)}

Since publication of the 2 Institute of Medicine reports, To Err is Human ${ }^{1}$ and Crossing the Quality Chasm, ${ }^{2}$ the public and government expect and demand higher quality and safer patient care. To accomplish its mission of improving health care by assessing and advancing the quality of resident physicians' education, ${ }^{3}$ the Accreditation Council for Graduate Medical Education (ACGME) encouraged competency-based education with the creation of 6 core competencies. Recently, the ACGME created the milestones, which emphasize competencybased developmental outcomes. The family medicine milestones, to become effective July 1, 2014, consist of 22 outcomes based on the 6 core competencies.

A mandate for family medicine residency programs is to ensure their graduates are able to provide safe health care to their patients. As programs begin to implement the milestones, an emerging complimentary theme is the entrustable professional activity (EPA), which is a way to translate competencies into clinical practice. ${ }^{4}$ Collectively, a set of EPAs for family medicine constitute the core clinical activities of a family physician, ${ }^{5}$ ie, what does a family physician do in practice and how do we know a graduate is competent to independently and safely practice those activities? Going beyond a checklist of behaviors, EPAs define the "knowledge, skills, and attitudes" integrated across the competency domains and the work that a family physician does. ${ }^{4}$

As family medicine is such a rigorous and diverse specialty, constructing a comprehensive list of EPAs is indeed a daunting task. One educator recommends a graduate medical education program have no more than 20 to 30 EPAs that are clear but not too detailed. ${ }^{6}$ An initial attempt at defining EPAs in family medicine included a list of 76 items that mostly focused on the ambulatory setting. ${ }^{6}$ Ideally, EPAs should be indepen- dently executable within a given time frame as well as observable and measurable. ${ }^{4}$ Ultimately, the EPAs should be a list of what the public can expect from their family physicians. Currently, a committee of family medicine leaders is drafting a list of EPAs for our specialty. They are expected to release the list this fall-intentionally coinciding with the anticipated Family Medicine for America's Health report.

The emergence of EPAs in family medicine is intended to support the milestones, and it is important to note their differences. Milestones follow each competency along a developmental continuum. While milestones detail individual competencies, real care delivery requires integration of these abilities in a more complex manner. ${ }^{5}$ For example, an EPA on care for the underserved/vulnerable patient would require a resident (on multiple occasions) to demonstrate knowledge of population health, advocacy, and cost awareness, and to employ team-based care, utilize IT resources, etc. Proficiency in an EPA requires mastery of several competencies, and goes well beyond ACGME program requirements, time spent on rotations, or patient numbers. The EPA assessments are based on specific observable activities throughout residency and not just a general impression.

EPAs can also be used to drive curriculum development at the residency level. Program directors should use EPAs as they are intended to strengthen professional standards, improve patient safety, and enhance outcomes. The implementation of EPAs is not meant to be burdensome; rather, they should help programs bridge the gap between initial competency-based assessments and real-world practice. EPAs will be particularly helpful for family medicine faculty who struggle with Likert scale numerical ratings.

We are in an exciting time in family medicine education as we look to incorporating milestones and EPAs into our residency programs. Implementation should produce higher quality graduates who will provide safe, quality care to their patients and communities. Natasha Bbuyan, MD and W. Fred Miser, $M D_{i}$

Gretchen M. Dickson, MD, MBA, James W. Jarvis, $M D_{\text {i }}$ Lisa Maxwell, MD, Michael Mazzone, MD, Karen Mitchell, $M D_{i}$ Stephen Scbultz, $M D_{i}$ Todd Shaffer, MD, MBA, Michael Tuggy, MD

\section{References}

1. Kohn LT, Corrigan JM, Donaldson MS, eds. To Err is Human: Building a Safer Health System. Washington, DC: National Academy Press; 2000.

2. Committee on Quality of Health Care in America. Institute of Medicine. Crossing the Quality Chasm: A New Health System for the 21st Century. Washington, DC: National Academy Press; 2001.

3. Accreditation Council of Graduate Medical Education. Mission. https://www.acgme.org/acgmeweb/tabid/121/About/ Misson,VisionandValues.aspx. Accessed Apr 24, 2014. 